\title{
Welcome to Volume 9 of Lung Cancer Management
}

\author{
Katherine Gordon*,1 \\ ${ }^{1}$ Future Medicine Ltd, Unitec House, 2 Albert Place, London, N3 1QB, UK \\ *Author for correspondence: k.gordon@futuremedicine.com
}

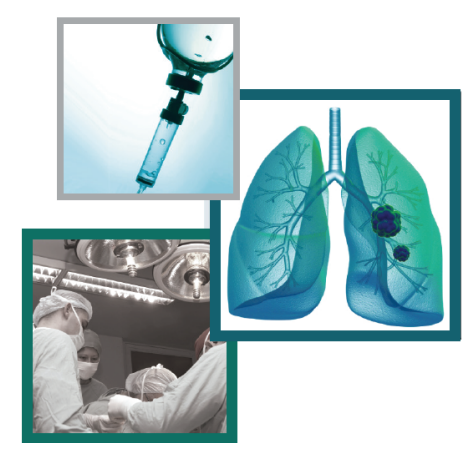

First draft submitted: 14 February 2020; Accepted for publication: 14 February 2020; Published online: 24 March 2020

As the new editor for Lung Cancer Management, it is with great delight that I welcome you to the first issue of Volume 9. 2020 is set to be another exciting year for the journal with new projects, new ideas and more high-quality content from all of our authors. However, before we start this new period, I would like to look back over the past year and our highlights from 2019.

\section{Content highlights}

In 2019, we have continued to publish content of a high standard; thanks to both our authors and reviewers. We have received a variety of different article types, including original research, case reports, opinion-based editorials and interviews. The research we have published this year has provided interesting and exciting developments in the field of lung cancer diagnosis and treatment, with each author providing a novel perspective on the field.

The most read article this year was a research article from Muhammad Afzal (Dartmouth-Hitchcock Medical Center, NH, USA) and colleagues on 'Clinical outcomes in non-small-cell lung cancer (NSCLC) patients receiving concurrent metformin and immune checkpoint inhibitors' [1]. In this study, the researchers determined the overall response and disease control rate in 50 NSCLC patients receiving immune checkpoint inhibitors, either with or without metformin. Although further prospective studies are needed to verify the long-term benefits of treating NSCLC with metformin in conjunction with immune checkpoint inhibitors, the study demonstrated that this treatment improves clinical outcomes for NSCLC patients.

Another popular article this year was a case report titled 'Pembrolizumab-induced necrotizing myositis in a patient with metastatic non-small-cell lung cancer: a case report' [2]. In this report, Kristiann Nackaerts (Katholieke Universiteit Leuven, Belgium) and colleagues discuss the diagnosis and treatment of a 57-year old patient presenting symptoms of pembrolizumab-induced myositis. The case highlighted the need for regular screening for treatment-induced myositis in all immunotherapy patients.

Our most widely shared article in 2019 was a review from Rodney Wegner (Allegheny Health Network Cancer Institute, PA, USA) and colleagues on stereotactic body radiation therapy in early stage NSCLC [3]. Over the last two decades clinical use of stereotactic body radiation therapy has dramatically increased and it is now considered the standard-of-care for inoperable early stage NSCLC. In this review, the authors discussed the historical basis of stereotactic body radiation therapy, examined the landmark trials and commented on current and future research areas.

\section{Reader demographics}

In 2019, the audience for Lung Cancer Management has continued to grow, both geographically and numerically. Overall, views have increased by an incredible 159\% in 2019 compared with 2018, with particular increases in readers from North America (191\%) and Africa (196\%).

We were pleased to see that in 2019 our research has continued to be read all around the world, with the highest number of our readers being from North America (46\%), Asia (31\%) and Europe (19\%; Figure 1). Specifically, the highest amount of our readers were from the USA (43\%), followed by China (9\%) and India (8\%). 
2019 Reader Demographics

North America

Asia

Europe

Australasia

Africa

$\square$ South America

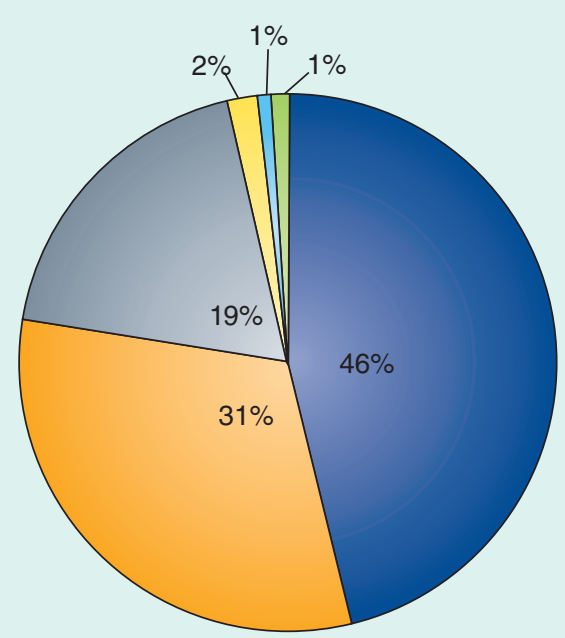

Figure 1. Proportion of readership demographics for Lung Cancer Management in 2019.

\section{Author Demographics}

North America

Asia

$\square$ Europe

$\square$ Africa

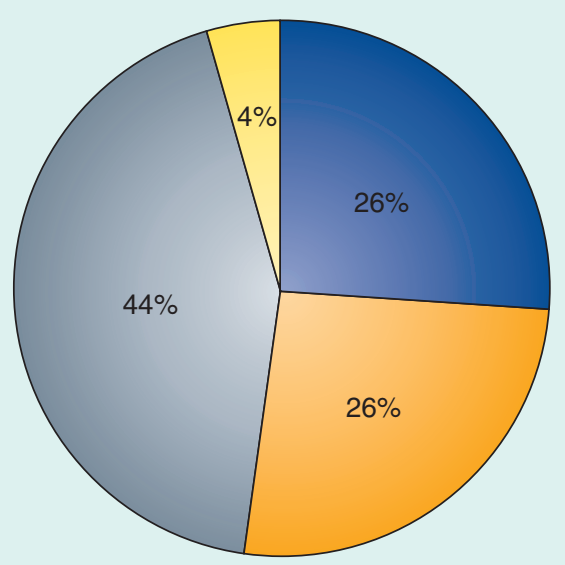

Figure 2. Proportion of authorship demographics for Lung Cancer Management in 2019.

\section{Author demographics}

In 2019, we have continued to receive high quality content from authors all over the world. Authors from Europe (43\%) were the biggest contributors to Volume 8 of Lung Cancer Management, followed by North America (26\%) and Asia (26\%; Figure 2).

We have seen a particular increase in the proportion of content received from Asia, which increased from $0 \%$ in 2018 to $26 \%$ in 2019 . Overall, the number of different countries from which our authors were from increased by $89 \%$ in 2019 compared with 2018, demonstrating how our international authorship is growing. 


\section{Editorial board}

We'd like to thank our editorial board for their continued input, be it in an ambassadorial, advisory or authorship role.

We have published some great content in collaboration with our editorial board members in 2019, such as the research article with editorial board member Sumitra Thongprasert (University of Chiang Mai, Thailand) and colleagues [4]. The study, titled 'Afatinib in locally advanced/metastatic NSCLC harboring common EGFR mutations, after chemotherapy: a Phase IV study', evaluated the efficiency and tolerability of second-line afatinib in patients with EGFR mutation-positive NSCLC following chemotherapy. The results of the study supported the use of afatinib as an effective second-line treatment.

Our international board offer invaluable assistance and advice that facilitates the publication process; we are excited to continue working together in the coming year. On this note, if you are interested in joining our advisory board or wish to provide feedback or suggestions for the journal, please do not hesitate to get in touch; we value any and all input that can contribute to the growth and development of the journal.

\section{Social media}

In 2019 we have continued to ensure our articles reach the largest possible audience by remaining an active presence on social media. If you do not already, we welcome you to follow us on Twitter (@fsglmt), where we share all newly published articles from our journal and news on recent developments in the field of lung cancer diagnosis and treatment. By using social media, we aim to reach all relevant stakeholders in the field of lung cancer management, including researchers, clinicians, charities, patients, academics/educators and patient advocates.

We have continued our partnership with the site Oncology Central [5], where our authors are provided with the opportunity to have their work featured on the Oncology Central website and be seen by its wide readership base. Registration to Oncology Central is free and allows you to keep up-to-date with the latest developments in cancer via unparalleled free access to the latest news, opinion, peer-reviewed journal articles, multimedia and exclusive content.

\section{Conclusion}

We appreciate any and all feedback from our readers regarding the direction of our content. Please do not hesitate to contact us with any suggestions of what you would like to see featured or any hot topics you feel should be covered this year in Lung Cancer Management. We welcome a wide range of unsolicited article proposals and would be delighted to hear from you.

Once again, I would like to thank all of the authors and reviewers who worked hard to make Volume 8 possible. We hope to continue building on the success of 2019 in 2020 and we are looking forward to another great year and the start of a great decade.

Financial \& competing interests disclosure

K Gordon is an employee of Future Science Ltd. The author has no other relevant affiliations or financial involvement with any organization or entity with a financial interest in or financial conflict with the subject matter or materials discussed in the manuscript apart from those disclosed.

No writing assistance was utilized in the production of this manuscript.

\section{Open access}

This work is licensed under the Attribution-NonCommercial-NoDerivatives 4.0 Unported License. To view a copy of this license, visit http://creativecommons.org/licenses/by-nc-nd/4.0/

\section{References}

1. Afzal MZ, Dragnev K, Sarwar T, Shirai K. Clinical outcomes in non-small-cell lung cancer patients receiving concurrent metformin and immune checkpoint inhibitors. Lung Cancer Manag. 8(2), LMT11 (2019).

2. Claus J, Can Den Bergh A, Verbeek S, Wauters E, Nackaerts K. Pembrolizumab-induced necrotizing myositis in a patient with metastatic non-small-cell lung cancer: a case report. Lung Cancer Manag. 8(2), LMT10 (2019).

3. Abel S, Hasan S, Horne ZD, Clonias A, Wegner RE. Stereotactic body radiation therapy in early-stage NSCLC: historical review, contemporary evidence and future implications. Lung Cancer Manag. 8(1), LMT09 (2019).

4. Thongprasert S, Geater SL, Clement D et al. Afatinib in locally advanced/metastatic NSCLC harboring common EGFR mutations, after chemotherapy: a Phase IV study. Lung Cancer Manag. 8(3), LMT15 (2019).

5. Oncology Central. www.oncology-central.com 